\title{
Reconhecimento Ideológico: Uma Reinterpretação do Legado de Gilberto Freyre sob a Ótica da Teoria do Reconhecimento
}

Ricardo Fabrino Mendonça ${ }^{1}$

Nathália França Figuerêdo Porto

1. Universidade Federal de Minas Gerais (UFMG), Belo Horizonte, MG, Brasil. E-mail: ricardofabrino@hotmail.com

D odem o reconhecimento e a valorização de certos sujeitos contribuir para sua opressão? Essa é uma questão a perpassar os debates contemporâneos sobre a teoria do reconhecimento na filosofia política. Depois da difusão da guinada da teoria crítica proposta por Axel Honneth a partir da noção de reconhecimento, vários autores e autoras questionaram o potencial opressivo da própria ideia de reconhecimento. Argumentou-se que o conceito poderia servir para escamotear assimetrias econômicas, engessar e essencializar identidades, ou mesmo alimentar a lógica que embasa a opressão humana (Fraser, 2003, 2008; Markell, 2003; McNay, 2008).

A partir dessas críticas, emergiram tentativas de resposta e de aprofundamento da discussão. Honneth apresentou sua visão sobre os perigos do discurso do reconhecimento em um texto intitulado "Recognition as Ideology". Nesse texto, ele discute como formas supostamente positivas de reconhecer o outro alimentam a opressão estrutural, servindo a propósitos que não os da emancipação humana. O presente artigo busca discutir essa ideia para pensar a forma como a questão racial aparece na obra de Gilberto Freyre (1900-1987). Em sua abordagem boasiana e neolamarckiana (Araújo, 1994), Freyre ressignifica a noção de raça até então trabalhada pelas Ciências Sociais brasileiras, conferindo-lhe certa maleabilidade e atribuindo a diferentes raças contribuições na criação miscigenada do Brasil. De um ponto de vista teórico, essa discussão abre espaço para abordar a forma como DADOS - Revista de Ciências Sociais, Rio de Janeiro, vol. 60, no1, 2017, pp. 145 a 172. 
determinadas injustiças sociais no Brasil podem ser investigadas à luz da noção de reconhecimento ideológico.

Em alguma medida, o texto se apresenta como um contraponto ao artigo de Avritzer e Gomes publicado na DADOS em 2013. No referido artigo, os autores buscam mobilizar a teoria do reconhecimento para pensar a questão racial e dialogam, fundamentalmente, com o legado de Freyre e suas implicações. Pretendemos mostrar que, embora rica e interessante, a análise oferecida pelos autores tem alguns limites na forma de mobilização da teoria do reconhecimento. Ela opera com uma clivagem problemática entre público e privado na leitura do debate entre Honneth e Fraser, além de desconsiderar a centralidade do conceito de falso reconhecimento para entender o lugar concedido ao negro e ao próprio conceito de raça na obra de Freyre. Sobre o segundo ponto, concordamos com os autores do referido artigo ao indicar que Gilberto Freyre é um autor que precisa ter sua obra analisada à luz das teorias do reconhecimento, mas buscamos evidenciar outras contribuições do trabalho de Honneth não exploradas por eles.

O artigo está estruturado em três partes. Na primeira delas, introduziremos a discussão do reconhecimento, com especial foco na discussão sobre o potencial opressivo de certas "conquistas" do reconhecimento e da noção de falso reconhecimento. Na sequência, exploraremos algumas das contribuições e dilemas do trabalho de Freyre no que tange à questão racial no Brasil. Na terceira parte, discutiremos a operacionalização da teoria do reconhecimento realizada por Avritzer e Gomes (2013) e buscaremos apontar como a própria noção de reconhecimento poderia contribuir para a superação de alguns dos problemas da referida análise. No escopo e espaço do presente artigo, não é nossa intenção apresentar uma análise mais estruturada das lutas raciais no Brasil assentada na proposta honnethiana de teoria crítica. Mais modesta, nossa proposta busca questionar uma aplicação realizada e chamar a atenção para outros potenciais de uma agenda de pesquisa fundada na contribuição de Honneth.

\section{O RECONHECIMENTO DO FALSO RECONHECIMENTO}

A teoria do reconhecimento já ocupa lugar relevante entre as teorias da justiça e nas discussões contemporâneas sobre teoria crítica. Com um histórico de quase três décadas de acalorados debates filosóficos e aplicações empíricas diversas, a teoria cresceu, diversificou-se e alar- 
gou-se. Independentemente dos perigos que essa expansão conceitual gerou, incluindo o fato de que há compreensões absolutamente distintas sobre o conceito, é possível dizer que houve a formação de uma considerável massa crítica em torno da teoria do reconhecimento.

Neste artigo, não cabe traçar um histórico da teoria do reconhecimento, mapear seus debates internos ou evidenciar a diversidade de concepções que a atravessam, mesmo porque já o fizemos em outros trabalhos (Mendonça, 2007, 2009, 2013). Embora ofereçamos, nos parágrafos que se seguem, uma breve menção introdutória à teoria, nosso foco se volta para a discussão mais específica da ideia de falso reconhecimento, a partir da qual apresentamos uma reflexão sobre o pensamento de Gilberto Freyre.

A concepção de reconhecimento aqui exposta é a de Axel Honneth. Delineada desde os anos 1980 e consolidada no início da década de 1990, a abordagem de Honneth coloca a ideia de autorrealização no cerne da justiça (Honneth, 1995, 2003a, 2003b). Ele aponta que as lutas por reconhecimento, no sentido de conflitos voltados à construção de gramáticas morais mais propícias a fomentar a autorrealização humana, movem tanto as transformações sócio-históricas como as vidas dos sujeitos. Em Honneth (2003a), lutas por justiça são conflitos que buscam fundamentalmente deslocar gramáticas morais que balizam as interações sociais e os processos de construção de selves.

Na condição de expoente da teoria crítica, Honneth discute a noção de reconhecimento como contendo caráter essencialmente emancipatório. Partindo do pressuposto de que a autorrealização é construída contextual e historicamente, Honneth defende que, na contemporaneidade, amor, direitos e estima se constituíram como domínios fundamentais da autorrealização. Isso quer dizer que vínculos afetivos fortes, direitos igualitários e a possibilidade de singularização são vistos como dimensões basilares do que significa ser humano e da vida em uma sociedade justa. Ainda de acordo com o filósofo de Frankfurt, o sentimento de indignação moral que, em certos contextos sociopolíticos, pode advir do desrespeito, impulsiona conflitos e lutas cotidianamente. Alguns desses conflitos podem se traduzir como pertinentes à coletividade, engendrando semânticas coletivas, e convertendo-se em lutas sociais. Essas lutas são a alma do processo de deslocamento e reconstrução de gramáticas morais, visto por Honneth como relevante à promoção da justiça. 
As ideias de Honneth sofreram várias críticas. Houve quem o criticasse por negligenciar a dimensão econômica da justiça (Fraser, 2003), por essencializar identidades (Markell, 2003; Fraser, 2003), por desconsiderar as relações de poder efetivamente existentes (McNay, 2008), por superestimar a dimensão emancipatória da ideia de direitos (Seglow, 2009; McNay, 2008), por não tratar o perigo das noções de estima e mérito (McBride, 2009), por não tematizar os riscos da ideia de cuidado nem analisar a divisão do trabalho por gênero (Young, 2007), por perder de vista a dimensão propriamente política da justiça (Deranty e Renault, 2007; Feldman, 2002) ou por colocar pouco peso na centralidade da justificação em uma teoria da justiça (Forst, 2007). Como já mencionado, essas discussões se desdobraram em respostas e debates, cabendo mencionar que o próprio Honneth busca endereçar várias dessas questões em publicações posteriores (Honneth, 2007, 2012, 2014).

Neste artigo, interessa-nos uma crítica específica que aponta para os riscos do reconhecimento e suas acepções possivelmente distorcidas. Ela aparece, por exemplo, nos trabalhos de Fraser (2008) que afirma que a força do discurso do reconhecimento teria servido para escamotear (e, portanto, para fortalecer) opressões existentes. A análise feita pela autora sobre a segunda onda do feminismo no final do século XX seria ilustrativa dos riscos de uma guinada rumo ao reconhecimento. O esvaziamento de questões econômicas e a perda de foco no trabalho promoveriam uma negligência sistemática de injustiças fundamentais (Fraser, 2008). A autora aborda, ainda, de que forma o pensamento de direita se engajaria nas discussões sobre reconhecimento cultural, de modo a distrair a atenção da esquerda sobre sua política econômica. Em um argumento muito interessante, ela afirma, também, que as igrejas teriam, na atualidade, mais êxito em dialogar com mulheres de classes pobres do que as feministas do Norte, justamente porque seriam capazes de lidar com a insegurança material onipresente na vida dessas pessoas.

Patchen Markell (2003) também critica o risco do discurso do reconhecimento, embora por uma perspectiva distinta. Fundamentado em Aristóteles e Arendt, Markell (2003) alega que o reconhecimento sempre implica um engessamento e que este está na base da reprodução da lógica da dominação. Em seu argumento, a luta de indivíduos e grupos para impor aos outros uma forma de autodefinição alimenta a lógica da soberania, que é causa da própria opressão humana. De alguma forma, a noção de reconhecimento empregaria categorias que, ao destacar 
características e condições particulares, fortaleceria a ideia de que os sujeitos podem fixar, de forma soberana e autônoma, a maneira como serão percebidos e significados. Assim, para Markell, o próprio reconhecimento seria um reconhecimento distorcido, que coloca a identidade à frente da ação e estanca sua dimensão processual.

Bader procura conceituar a noção de misrecognition - ou reconhecimento falso, enviesado ou ideológico -, de modo a permitir uma compreensão mais complexa da opressão. De acordo com ele, misrecognition

reduz as capacidades e agências de 'pessoas sem poder', de modo que elas não apenas não tenham recursos e oportunidades, mas também estejam inconscientes das injustiças e incapazes de articular seus próprios interesses e necessidades particulares (Bader, 2007:240; tradução livre).

Ele parte da noção de hierarquia de prestígio para discutir a centralidade do privilégio, gerado por formas diversas de poder. Para Bader (ibidem:244), a formação de hierarquias se manifesta em uma mistura de exploração, opressão, exclusão e marginalização, cujas fontes residem na distribuição desigual de recursos distintos, mas que se constrói como uma nova fonte de desigualdade pautada pelo prestígio. Bader defende que o conceito de misrecognition deve ser entendido como uma forma de desrespeito dentre muitas possíveis. Na visão dele, transformações efetivas devem se voltar para as assimetrias de poder que sustentam as hierarquias de prestígio.

O livro The Politics of Misrecognition, organizado por Simon Thompson e Majid Yar (2011) também explora, por meio de uma série de estudos empíricos, situações de não reconhecimento ou de falso reconhecimento. Diante da multiplicidade de formas de desrespeito existentes, Thompson e Yar (2011) explicam que, diferentemente do não reconhecimento (que seria uma negação da condição humana), o falso reconhecimento (misrecognition) seria uma forma distorcida ou incompleta de reconhecer. Na mesma linha, Ana Carolina Ogando (2012) busca evidenciar, em análise histórica sobre o pensamento feminista no Brasil, a maneira sutil com que supostas práticas emancipatórias reproduzem o desrespeito, por meio do misrecognition. É preciso deixar claro que, ao falar em formas distorcidas de reconhecer, tais autores não implicam a existência de uma única forma de reconhecimento possível. O objetivo é simplesmente o de argumentar que há formas de "valorização de 
identidades" que acabam por alimentar a opressão dos grupos e sujeitos supostamente "valorizados".

Mendonça (2014) argumenta, assim, que a própria dinâmica do reconhecimento é atravessada por formas de misrecognition, na medida em que não existe um estágio final de justiça pleno e completo. É preciso entender a dimensão processual da justiça, sendo que as lutas por reconhecimento são atravessadas permanentemente por dimensões emancipatórias e por novas formas de injustiça e opressão. As lutas são sempre tortuosas e inerentemente contraditórias. O que é compreendido como misrecognition atualmente poderá tanto se mostrar como uma forma de não reconhecimento no futuro, como se desdobrar em formas mais emancipatórias de reconhecimento. Sendo assim, deve-se compreender o conceito de reconhecimento em seu caráter processual, e não necessariamente dicotômico.

Honneth reconhece a necessidade de discutir a ideia de falso reconhecimento (aqui tomado como uma forma de misrecognition), admitindo que a retórica do reconhecimento público pode reproduzir a opressão. Para ele,

longe de fazer uma contribuição duradoura para as condições da autonomia dos membros de nossa sociedade, o reconhecimento social [em alguns casos específicos] parece meramente servir à criação de atitudes que se conformam ao sistema dominante" (Honneth, 2007:323; tradução livre).

Ele aponta que é simplesmente equivocado criticar a teoria do reconhecimento por negligenciar a questão da sujeição e do poder em suas origens (como o fizeram Fraser ou McNay, por exemplo), mas pondera a necessidade de desenvolver melhor a ideia de reconhecimento como ideologia.

O filósofo alemão inicia esse aprofundamento evidenciando que nem toda forma de desrespeito pode ser entendida como exemplo de reconhecimento ideológico. Há formas de desrespeito que nada têm a ver com o reconhecimento e são a sua negação em um nível mais fundamental. Esse seria o caso, por exemplo, dos discursos de intolerância declarada, a exemplo do racismo, da xenofobia e da homofobia explícitos, os quais não estão necessariamente preocupados em se formatarem como discursos velados. Tais discursos seriam casos de não reconhecimento (non-recognition), negando a própria humanidade do outro. 
Justamente para entender a nuance do reconhecimento ideológico e distingui-lo do não reconhecimento tout court, Honneth precisa delimitar os elementos que atravessam o termo reconhecimento. Para ele, há quatro premissas para que se fale em reconhecimento. Primeiramente, há alguma forma de afirmação de qualidades positivas. Em segundo lugar, trata-se de uma ação que ultrapassa o espaço do simbólico e envolve formas concretas de comportamento. Em terceiro, esses atos são delimitáveis como expressões de uma intenção de reconhecer, não sendo efeitos colaterais de outras ações. Em quarto lugar, o reconhecimento possui muitas subespécies. Em suma, "reconhecimento deve ser entendido como um gênero que compreende várias formas de atitudes práticas cuja intenção primária consiste em um ato particular de afirmação de uma outra pessoa ou grupo" (ibidem:330).

Nesse sentido, para Honneth, "reconhecer alguém é perceber em sua pessoa uma qualidade de valor que nos motiva intrinsecamente a não nos comportarmos mais egocentricamente" (ibidem:337). O problema, contudo, é que algumas formas de dar valor ao outro acabam apenas por motivá-lo a desempenhar certas tarefas e ações de maneira natural. Esse é o caso, por exemplo, da valorização de experiências específicas, como a das mulheres como mães ou da valorização do funcionário flexível e dedicado que faria qualquer sacrifício pela empresa. Nota-se, aqui, uma valorização de sujeitos, que não implica a negação de sua condição de humanidade (non-recognition), mas que alimenta processos de subordinação desses mesmos sujeitos.

Tais casos exemplificam o que Honneth chama de reconhecimento ideológico, que teria três condições básicas. Em primeiro lugar, tal forma de reconhecimento se ancora em classificações não discriminatórias. "Para serem eficazes em virtude do reconhecimento social que provêm, ideologias não podem excluir seus destinatários, mas precisam contribuir para sua integração" (ibidem:338). Em segundo lugar, essa ideologia precisa ser crível. As pessoas precisam se identificar com os discursos a elas endereçados para que performem as tarefas e ações que sustentem o status quo. Em terceiro lugar, a valorização ideológica "precisa ser contrastante, no sentido de dar expressão a um novo valor particular ou realização especial" (ibidem:339). Os sujeitos precisam se sentir distintos. Baseando-se em Foucault, Honneth alega que o reconhecimento ideológico gera um poder produtivo (e não repressivo) que fomenta necessidades, desejos e ações que reproduzem a dominação social. É, por exemplo, a mãe que se desdobra nos cuidados domés- 
ticos ou o trabalhador que vê a flexibilidade no trabalho como forma de se distinguir dos demais colegas.

Entendemos, assim, que o reconhecimento ideológico trabalhado por Honneth é uma forma de expressão do falso reconhecimento ou misrecognition, distinguindo-se claramente do não reconhecimento (non-recognition). O difícil, todavia, como o próprio Honneth (2007) admite, é diferenciar formas de reconhecimento ideológico (ou falso reconhecimento, em nossas palavras) de formas de reconhecimento efetivo, mesmo porque o que parece ideológico em um dado momento pode revelar-se emancipatório na sequência e vice-versa. No entanto, para ele, são particularmente perigosas formas de reconhecimento meramente simbólicas, que "não levam a modos de comportamento que dão expressão real ao efetivo valor articulado no ato original" (ibidem:345). Mudanças em termos de políticas e de definições legais, bem como redistribuição de recursos, são, assim, muito importantes para Honneth.

Com base nessas ideias, podemos nos mover para a segunda parte do artigo que apresenta, em linhas gerais, a compreensão de Gilberto Freyre sobre a questão racial no Brasil e seus desdobramentos. Como veremos a seguir, Freyre alimenta justamente uma forma de reconhecimento ideológico na guinada que realiza no pensamento sobre raça na primeira metade do século XX.

\section{MISCIGENAÇÃO, HIBRIDISMO E MISRECOGNITION: O LEGADO DE GILBERTO FREYRE}

Gilberto Freyre alterou profundamente a maneira como a categoria raça é pensada no Brasil. Deve-se a ele, em grande medida, a contestação do racismo biológico de base spenceriana, inspirado em teses eugenistas, que guiara grande parte dos estudos acerca das relações raciais no Brasil na passagem do século XIX para o XX. Freyre desloca a maneira como as raças eram compreendidas no Brasil até então, dotando-lhes de certa maleabilidade e enfatizando as contribuições de diferentes matrizes raciais na construção de um Brasil miscigenado e culturalmente híbrido. Entende, ainda, a lógica da interação das raças não como mera imposição de um grupo sobre outro, mas como intercâmbios geradores de deslocamentos mútuos. Com isso, estimula a contestação da perspectiva de um antagonismo entre polos raciais estanques (Thomaz, 2002; Bastos, 2006, 2012). 
Araújo (1994) indica que o trabalho desenvolvido por Freyre, por mais que seja conhecido como uma proposição do esvaziamento da ideia de raça, contém a indubitável presença dessa variável, ainda que de forma pouco definida em seus textos. Freyre adota, de acordo com Araújo, uma definição neolamarckiana de raça, muito popular entre os estudiosos sociais da América Latina entre os séculos XIX e XX ${ }^{1}$ (Degler, 1971). Esta noção indicaria que o ambiente físico opera como uma categoria interveniente entre raça e cultura, mediando as relações entre esses dois conceitos.

Para compreender com mais rigor o nível de ruptura que Freyre propõe em relação aos autores das chamadas teses eugenistas, é necessário entender o seu ponto de partida. Nas décadas que precedem os escritos de Gilberto Freyre, o debate acerca das relações raciais e da posição do negro na sociedade brasileira estava particularmente dominado pela tese da eugenia, preconizada por grupos de biólogos, médicos e teóricos sociais europeus. De acordo com muitos estudiosos da época, que se dedicaram a debater as relações raciais no Brasil, negros e mestiços seriam responsáveis por determinadas mazelas biológicas e por imprimir à formação do povo brasileiro características nocivas como a indolência e a excessiva tendência à sexualização (Schwarcz, 1993).

As ideias de Nina Rodrigues, Silvio Romero e Oliveira Vianna, por exemplo, buscavam compor uma teoria pretensamente científica de bases racistas, que subsidiaria a política nacional de branqueamento (por meio do incentivo à imigração europeia e a restrição à imigração oriental, considerada à época o "perigo amarelo"). Condenando a miscigenação, tal perspectiva alegava que a mistura racial cumpriria uma função degenerativa na formação do povo brasileiro. Em Nina Rodrigues (1899), o evolucionismo social se articula à antropologia criminal, para vincular a decadência do país (ou da Bahia, mais especificamente) a negros e mestiços. Em Mestiçagem, Degenerescência e Crime (publicado pela primeira vez em 1899), ele advogava que raças são espécies distintas, argumentando, com base na craniometria, que a degenerescência derivaria da mestiçagem. Como indicadores dessa degenerescência, Rodrigues mencionava fatores que vão do "alcoolismo" à "surdo-mudez", passando pela "idiotia", pela "impulsividade" e pela "tendência a engordar". Resultados de um "amálgama defeituoso", mesmo os mestiços aparentemente inteligentes seriam superficiais e incapazes de esforço. 
Paralelamente, na literatura documental de Euclides da Cunha, o detalhado olhar sobre o Brasil profundo de Os Sertões (publicado em 1902) revela um mestiço que deriva do ambiente geográfico em que se insere. Se o sertanejo tem qualidades como a força e a agilidade (de um Hércules-quasímodo), a mestiçagem é perniciosa, misturando raças distintas e gerando um povo improvisado, decaído e sem energia, facilmente manobrável. Aliás, o sertanejo só tinha qualidades, porque seu isolamento no interior do país teria permitido uma reprodução uniforme, gerando um novo tipo humano (quase sem mescla de sangue africano), que poderia vir a evoluir².

Oliveira Vianna (1987) sustenta o determinismo biológico e geográfico, fortalecendo teses racistas, desde a obra que o tornou célebre: Populações Meridionais (publicado pela primeira vez em 1920). Em Raça e Assimilação (Vianna, 1934), ele se apoia na psicometria - metodologia amplamente difundida à época - para questionar a tese igualitarista e para vincular predisposições patológicas e de inteligência a diferentes tipos físicos. Defensor do branqueamento, Oliveira Vianna via os negros como fantasiosos, imediatistas e cruéis, e as populações indígenas como essencialmente desconfiadas e desgostosas (Ramos, 2003:588).

Nesse contexto, é possível perceber que a ruptura proposta por Freyre em sua análise do microcosmo colonial brasileiro não é pequena. A tese da antropofagia luso-brasileira defendida por Freyre consistiria no destaque à capacidade da cultura brasileira de adaptar os diferentes costumes da matriz civilizatória ao clima e ao ambiente social brasileiro, por meio de "antagonismos em equilíbrio"3. De acordo com ele,

todo brasileiro, mesmo o alvo, de cabelo louro, traz na alma, quando não na alma e no corpo [...] a sombra, ou pelo menos a pinta, do indígena ou do negro. Na ternura, na mímica excessiva, no catolicismo em que se deliciam nossos sentidos, na música, no andar, na fala, no canto de ninar menino pequeno, em tudo que é expressão sincera de vida, trazemos quase todos a marca da influência negra. Da escrava ou sinhama que nos embalou. Que nos deu de mamar. Que nos deu de comer, ela própria amolengando na mão o bolão de comida. Da negra velha que nos contou as primeiras histórias de bicho e de mal-assombrado. Da mulata que nos tirou o primeiro bicho-de-pé de uma coceira tão boa. Da que nos iniciou no amor físico e nos transmitiu, ao ranger da cama-de-vento, a primeira sensação completa de homem (Freyre, 2001:178). 
Segundo Omar Ribeiro Thomaz, sob o ponto de vista de Freyre, a cultura brasileira se destacaria, justamente, por sua capacidade de assimilação (Thomaz, 2002:189). Gilberto Freyre representa, assim, uma importante insurreição contra os trabalhos das teses eugenistas, sendo acompanhado por Sérgio Buarque de Hollanda e, posteriormente, por Darcy Ribeiro. Com sua linguagem "quente e oleosa, com cheiro de manhã e viços de planta nova" (Coutinho, 2005:102), Freyre reconstrói a compreensão das raças no Brasil, questionando as bases do racismo spenceriano vigente. É importante destacar que a intenção freyriana, tanto em Casa Grande \& Senzala (publicado em 1933) quanto em Interpretação do Brasil (compêndio de palestras realizadas por Freyre nos anos 1940), não é a de construir arquétipos heroicos individuais do Brasil colonial, e, sim, compreender a produção de uma cultura propriamente brasileira oriunda do encontro desses múltiplos sujeitos.

A adaptabilidade e a conformação social produtoras de um cenário propício à mistura racial devem, portanto, ser consideradas em Freyre como uma forma de falar sobre o conceito de raça. A influência do ambiente na concepção de cultura de Freyre é verificada em passagens de Casa Grande E Senzala, nas quais o autor destaca que os negros africanos, com "sua predisposição como que biológica e psíquica para a vida nos trópicos, [...] [s]ua maior fertilidade nas regiões quentes, [s]eu gosto de sol, [s] ua energia sempre fresca e nova quando em contato com a floresta tropical (Freyre, 1973:307-308)", adaptara-se à vida no Nordeste brasileiro. Nesse sentido, a orientação neolamarckiana assumida por Freyre, na exposição de seus conceitos de raça e cultura, torna-se mais evidente. A propósito, o autor pernambucano trabalharia com um conceito mais amplo de cultura, não necessariamente limitado às ideias de solidariedade, identidade e homogeneidade, recorrente em alguns estudos antropológicos.

Em Casa Grande \& Senzala, Freyre delineia a colonização brasileira como uma empreitada privatista, pensando os engenhos como fundamento da organização nacional. Ali teriam se estruturado formas de produção, mas também de cultura e de comportamento. A monocultura latifundiária, a predisposição portuguesa ao hibridismo e a necessidade da miscigenação (diante da escassez de mulheres brancas) teriam gerado um país misturado e marcado por relações inter-raciais assimétricas, ainda que "açucaradas". Da mistura de brancos, negros e indígenas teria surgido, assim, uma sociedade particular, com deslocamentos mútuos e hibridismo na linguagem, nos costumes, nas 
práticas: um Brasil miscigenado, de religiosidade sincrética e lírica e de convivência inter-racial. A plasticidade característica do ambiente colonial seria a resultante da soma entre mobilidade, aclimatabilidade e miscibilidade, e a suposta degeneração dos mestiços, de que tanto falavam seus contemporâneos, não seria genética, mas fruto das condições de vida a que o latifúndio monocultor submetia muitas pessoas.

É bom lembrar que Freyre não é completamente indiferente às assimetrias e à violência que atravessam as relações raciais no Brasil (Ribeiro, 1995), ao contrário do que estabelecem muitas das interpretações feitas sobre o seu trabalho. Não lhe passa despercebida a existência de uma desigualdade social que estabelece com clareza, que "se a casa grande era para morar e existir plena e autonomamente, a senzala seria o lugar onde se vivia, ou melhor, sobre-vivia, como uma não pessoa ou morto vivo social" (DaMatta, 2004). Freyre também reconhece que, sob o regime escravocrata, a dominação senhorial exercida sobre o negro se estendia patriarcalmente sobre as mulheres (Degler, 1971). A tematização da dominação em sua obra é clara em seu desenvolvimento da ideia de sadomasoquismo, a qual aborda o prazer sádico de produzir sofrimento e o prazer de uma submissão projetada na imagem invertida do outro. Sugere, ainda, que a convivência entre o catolicismo português (altamente híbrido, com um forte apelo ao "gosto de carne") e a manutenção de violências nas relações senhoriais e patriarcais resultava em uma combinação entre inferno e paraíso.

Disso Freyre deriva o gosto pelo poder e pela autoridade no Brasil, ilustrado por várias formas de messianismo, autoritarismo ditatorial, mandonismo e patrimonialismo com que as elites brasileiras dirigiam o aparato estatal. No entanto, a própria tese do sadomasoquismo - que Freyre desenvolve em sua exposição das inúmeras violências cometidas no ambiente colonial - já envolve uma culpabilização do oprimido, além de sedimentar o caminho para o surgimento da tese da democracia racial. Em Freyre, a relativa suavidade da miscigenação apareceria na possibilidade de mobilidade vertical na sociedade e na inexistência do racismo institucionalizado, que se notava em outros contextos, como o dos Estados Unidos. Baseando-se em Boas, Freyre assume a constituição de grupos com laços capazes de promover a superação de antagonismos (Freyre, 2004:86).

Essa ideia atravessa sua obra. Em Sobrados e Mucambos (2004), o autor indica que "[...] excetuada a confraria católica, foi no escravo negro que 
mais ostensivamente desabrochou no Brasil o sentido de solidariedade mais largo que o de família sob a forma de sentimento de raça, e ao mesmo tempo, de classe" (Freyre, 2004:243). Roberto DaMatta, em seu prefácio ao livro, indica que Freyre tem, na citada obra, o objetivo de ressignificar a contribuição africana e seu potencial civilizador para a história do Brasil, aliando a matriz africana à portuguesa e à indígena.

Em virtude da originalidade de seu trabalho, Freyre é, obviamente, alvo de muitas críticas. Acusado de conservadorismo ${ }^{4}$ e de associação com a ditadura militar ${ }^{5}$, ele é visto como um autor importante na manutenção de assimetrias históricas no Brasil. Reis (2002) o interpreta como um neovarnhageniano, que saúda a dominação lusófila, patriarcalista e escravista. Bastos (2006) aponta a hipocrisia do discurso igualitário que faz uma ponte direta (e implausível) entre miscigenação e democracia. Lehmann (2008) assinala as ambivalências de seu pensamento e a combinação de influências nem sempre coerentes.

As críticas deixam claro o lugar ambíguo ocupado por Freyre na interpretação da questão racial no Brasil. Por um lado, ele enfrentou a desvalorização de negros e indígenas e os colocou no cerne da formação social do Brasil, transitando entre as noções de raça e cultura. Produziu uma interpretação voltada para a afirmação das qualidades positivas de diferentes grupos, moldando comportamentos e práticas sociais que atravessaram o século XX. Ao fazê-lo, questionou classificações discriminatórias, rompendo com a tese da degenerescência do mestiço, e construiu uma narrativa crível que valorizava diferentes sujeitos por suas características e ações: a higiene e o furor indígenas; a suavidade, a rebeldia contra privilégios e a flexibilidade dos portugueses; a adaptabilidade, a bondade e a doçura dos negros.

Cada um desses grupos teria sua relevância, sua beleza, sua contribuição para a configuração de um todo, que se apresentava como passível de harmonia, ainda que seu destaque dos componentes positivos de cada matriz seja balizado pelo ambiente social. Nesse sentido, importa destacar que a acepção neolamarckiana de raça presente em Freyre, ainda que inspirada em uma perspectiva biológica, não tira do autor uma visão positiva sobre o papel das diferentes raças e da contribuição feita por cada uma na constituição do que se convencionou chamar de povo brasileiro.

Por outro lado, a dimensão racial presente em sua obra não invalida a percepção de que Freyre gera um reconhecimento ideológico (ou 
misrecognition), pelo fato de limitar o espectro de construção pública da identidade do negro, predefinindo suas contribuições e engendrando um tipo de acomodação que aplaca antagonismos. Assim, o falso reconhecimento alimentado por Freyre se anuncia na desconsideração da multidimensionalidade identitária e na negligência ao fato de a construção da identidade ser marcada por fenômenos igualmente relevantes como a exploração do trabalho forçado, a herança de exclusão social e a resistência engendrada por essa prática. Evidentemente, o pilar das contribuições culturais de negros à formação social do Brasil discutidas por Freyre (língua, culinária, música, formas de tratamento) tem sido reivindicado pelo ativismo negro, com vistas a incentivar mais visibilidade ao protagonismo da população negra no debate público brasileiro (Guimarães, 1999; Telles, 2003; Bailey, 2009). Não obstante, as possibilidades de construção identitária e de autonomia não devem se resumir ao âmbito cultural, como Freyre faz parecer.

Outra manifestação de falso reconhecimento observada na teoria de Freyre acerca das relações entre negros e brancos no Brasil se refere à excessiva corporalização e sexualização da herança negra no imaginário brasileiro, especialmente das mulheres negras e mulatas. Associada à musicalidade, tida por Freyre como um dom natural herdado dos negros africanos, a hipersexualização do corpo negro levou as mucamas e escravas de ganho a serem exploradas pelos senhores de engenho, que se serviam de seus corpos vulnerabilizados pelo cativeiro a que estavam submetidas. Quando suas formas curvilíneas deixavam de existir, mais uma vez o reconhecimento do valor da mulher negra resumia-se à sua contribuição como escrava para amamentação e criação das crianças brancas, bem como os afazeres domésticos.

A consideração freyriana em relação ao lugar do negro na sociedade colonial desconsidera, ainda, as experiências de vexação e raiva suscitadas pela escravidão e pela violência simbólica. Como bem destaca Ribeiro (1995:77), "nenhum povo que passasse por isso [as agruras e sofrimentos da condição de escravo] como sua rotina de vida, através de séculos, sairia dela sem ficar marcado indelevelmente". Dessa forma, Freyre negligencia o histórico de lutas, resistências e confrontos de negros e negras na história do Brasil.

Assim, à mesma proporção em que provocou ruptura com a perversa tese da eugenia, Freyre acabou por limitar e definir a posição do negro na matriz civilizatória brasileira, alimentando ideias como a de hiper- 
sexualização e a de que negros são mais talentosos para profissões artísticas e musicais do que para atividades burocráticas, científicas e políticas. É dessa tensão que resulta a força do reconhecimento ideológico semeado por Freyre, que cria as condições para a manutenção de estruturas de interpretação e de padrões de ação opressivos. Ao suavizar a dominação de negros e indígenas, imputar-lhes parte da culpa pela opressão e projetar uma sociedade harmoniosa a partir do convívio afetivo, Freyre apazigua os atritos que atravessam os encontros interraciais e a situação extremamente desrespeitosa a que negra(o)s e indígenas foram e são submetida(o)s ao longo de nossa trajetória histórica. Questionando o racismo institucionalizado pela ciência e louvando a inexistência de um racismo aberto no país, Freyre fortalece as bases de reprodução do racismo sutil e velado que molda comportamentos, desejos, e compreensões de mundo no país ainda nos dias atuais.

Freyre, nesse sentido, não rompe de maneira profunda a "gramática moral" do contexto em que se insere, contribuindo para legitimar a subalternidade dos negros ${ }^{6}$. A valorização das contribuições deles não fomenta um questionamento mais efetivo das hierarquias e assimetrias sociais. O reconhecimento ideológico, ou misrecognition, gerado pela suposta redenção freyriana da mestiçagem não contribui de forma mais estrutural para a redução das condições de desrespeito e opressão a que tais sujeitos estão submetidos. Trata-se de uma valorização simbólica (estereotipada) que não altera práticas e formas de distribuição de recursos existentes. Ao contrário, e como advoga Honneth (2007), o reconhecimento ideológico à la Freyre reproduz as estruturas de dominação, interpelando os próprios oprimidos no sentido de apoiarem a sociedade que os oprime.

Essa interpretação honnethiana do lugar de Gilberto Freyre no pensamento sobre raça no Brasil é distinta da operacionalização feita por Avritzer e Gomes (2013). Na última seção deste artigo, voltamo-nos para a análise feita pelos autores, com o objetivo de assinalar alguns de seus limites. Embora concordemos com o argumento geral dos pesquisadores, entendemos que a mobilização da teoria do reconhecimento feita por eles padece de alguns problemas.

\section{RECONHECIMENTO, RAÇA E DEMOCRACIA}

Nesta seção, procuramos sistematizar a noção de misrecognition e sua recorrência na obra de Gilberto Freyre, para descortinar a forma com 
que o conceito tem sido usado (especialmente na interpretação das relações raciais no Brasil). Leonardo Avritzer e Lilian Gomes (2013) fazem interessante tentativa de mobilização das teorias do reconhecimento para a reflexão sobre o problema racial brasileiro. $\mathrm{O}$ argumento dos autores é o de que o mito da democracia racial de Freyre teria gerado uma negligência institucional em relação à opressão dos negros no país. De acordo com eles, as mudanças geradas pela Constituição de 1988 (com a introdução de artigos de viés racial) e pelo Estatuto da Igualdade Racial foram muito importantes para superar esse silenciamento institucional histórico sobre a injustiça. No entanto, ainda seria necessário encontrar mecanismos para que as mudanças do estatuto legal afetassem o âmbito social e privado, promovendo estima social.

Na visão dos autores, Honneth proporia

uma teoria do reconhecimento enquanto uma estrutura de aceitação do self por outros indivíduos, localizando na esfera privada, por meio do amor e da amizade, o elemento fundamental do processo de reconhecimento da diferença" (Avritzer e Gomes, 2013:39).

De maneira distinta, afirmam os pesquisadores, "Nancy Fraser aborda a dimensão política do processo de reconhecimento como a aceitação do self por meio de uma concepção de justiça que exerce o papel de reparação em relação às injustiças passadas" (idem).

Ainda de acordo com eles, a "política racial brasileira [esteve tradicionalmente] centrada naquilo que Honneth denomina como o campo da autoestima" (ibidem:45), ao enfatizar a exaltação de valores culturais, como a capoeira e o samba. Tratar-se-ia de uma valorização da miscigenação "sem o estabelecimento de políticas que garantam a igualdade de status entre os diferentes grupos" (ibidem:46). A política brasileira "de inclusão pela esfera privada" teria tido consequências muito próximas às da segregação oficial nos Estados Unidos. Nesse sentido, a ideia de paridade de participação de Fraser ofereceria um caminho para a correção institucional da tendência que perpassa a história do Brasil de, tradicionalmente, não legislar sobre raça.

Avritzer e Gomes argumentam que as políticas de ação afirmativa no Brasil têm consequências muito positivas ao buscar soluções para a assimetria de status institucionalizada no país. Eles admitem, contudo, que apenas a mudança legal não é suficiente, fazendo-se necessária uma desnaturalização do racismo nas relações sociais. A contribuição de 
Honneth, para eles, estaria justamente neste ponto, como outro "momento" de garantia de "reconhecimento - estima social" (ibidem:59).

O texto traz interessante apresentação das lutas de movimentos negros no país, questiona o mito da democracia racial (oriundo, em grande medida, dos escritos de Freyre) e advoga a necessidade de articular transformações institucionais (por meio de políticas públicas) e mudanças culturais no combate à opressão histórica a que negros estão submetidos no país. Estamos de pleno acordo com estes pontos. No entanto, a forma de operacionalização da teoria do reconhecimento realizada pelos autores parece problemática, o que tem implicações não apenas conceituais, mas também prático-políticas.

Avritzer e Gomes (2013) partem da premissa de que Honneth faz uma discussão privada da formação do self, que negligencia a centralidade das mudanças institucionais, públicas e políticas na transformação de situações de opressão. Nesse sentido, eles acabam por transformar a abordagem de Honneth em uma discussão sobre a possibilidade de selves virem a ser aceitos por outros. Visto que a aceitação não implica necessariamente tratamento justo, o que fica evidente na questão racial no Brasil, eles procuram corrigir o suposto privatismo honnethiano (que, então se torna próximo de Freyre) pela via das políticas públicas específicas que promoveriam paridade de participação, aos moldes de Fraser. O privado voltaria, então, como uma espécie de segundo momento, ou etapa, da promoção da justiça, capilarizando socioculturalmente uma igualdade de status construída politicamente.

O problema dessa leitura é que ela acaba por desconsiderar (1) que Honneth também se mostrou crítico às visões essencialmente simbólicas de reconhecimento que promovem aceitação e/ou valorização sem mudanças estruturais; e (2) que Honneth não opera com um enfoque privado (ou pré-político) em sua discussão sobre os processos de formação do self.

A discussão do reconhecimento como ideologia, que mobilizamos para pensar o legado de Freyre, mostra que Honneth não tem em vista uma reles valorização dos sujeitos. Ao contrário, ele entende como essa valorização pode sustentar práticas opressivas. A visão do negro doce, forte e sensual não descortina possibilidades mais efetivas de autorrealização. O "reconhecimento" de seu papel na cultura nacional não cria oportunidades mais concretas de contestação da opressão estrutural a que está cotidianamente submetido. Essa ideologia de valori- 
zação não é emancipatória, porque pode gerar acomodação, sustentando um apaziguamento dos conflitos em nome de uma suposta democracia racial. O reconhecimento ideológico é falso reconhecimento (misrecognition) não porque limitado ou incompleto, mas porque incapaz, em sua base, de promover justiça.

Isso nos conduz ao segundo ponto. Não nos parece adequado reduzir a contribuição de Honneth a uma discussão sobre a esfera privada. Em primeiro lugar, porque Honneth tem uma ampla discussão sobre a dimensão estrutural das injustiças, que atravessam sua obra e ficam muito claras no tratamento da questão da dominação de classe, na abordagem dos paradoxos do capitalismo e em suas discussões mais recentes sobre liberdade (Honneth, 1995, 2007, 2012, 2014; Hartmann e Honneth, 2006) ${ }^{7}$. Vale lembrar que a própria tese de doutorado de Honneth, na qual sua agenda de pesquisa dos anos 1980 está enunciada, chama-se Critique of Power (1991). Ainda que com um enfoque distinto desses trabalhos originais, seu livro mais recente Freedom's Right (2014), aborda a economia de mercado e o papel das instituições e do direito na teoria do reconhecimento. Esses aspectos estão no cerne do que Honneth (2003a) discute no seu livro mais conhecido sobre as lutas por reconhecimento. O filósofo alemão está fundamentalmente preocupado com padrões estruturados e institucionalizados de desrespeito que se manifestam nas práticas sociais.

Justamente por isso, e em segundo lugar, Honneth não pensa os processos de formação do self como privados (ou pré-políticos). Tais processos são essencialmente públicos (e políticos), na medida em que ocorrem no interior de uma sociedade marcada por certas estruturas de poder. O processo de formação do self permite vislumbrar a política em um nível mais fundamental e se configura, na própria base da transformação da sociedade, com suas instituições e práticas. O processo de formação dos selves está no cerne das lutas sociais que alimentam os choques entre gramáticas morais que impulsionam a mudança política. Honneth discute o self não porque está preocupado com o sentimento de cada indivíduo, mas porque entende que a sociedade justa é aquela que cria condições sociais para que esses indivíduos floresçam e se realizem e porque acredita que os sentimentos humanos indiquem trilhas de lutas contra injustiças. O florescimento humano, obviamente, depende das condições estruturais de uma sociedade e, portanto, das leis que regem a comunidade política e das políticas públicas por ela implementadas. 
Em Honneth (1995, 2003b, 2012), a noção de igualdade ocupa lugar absolutamente central e as instituições políticas têm relevância fulcral na promoção de uma sociedade mais igualitária em que "todo mundo" possa ser "cada um". Fica claro, ainda, que a dimensão da estima social, que Avritzer e Gomes (2013) utilizam ao longo do texto quase que como síntese da proposta honnethiana, não pode ser reduzida a uma aceitação simbólica de caráter meramente valorizativo que tenha consequências psicológicas positivas (Mendonça, 2009, 2011). Ao discutir a noção de estima, Honneth pensa no direito à singularidade, que está alicerçado no princípio da igualdade. Não por acaso, ele frisa a questão da simetria da estima (Honneth, 2003a).

Com isso, podemos voltar à questão racial e ao caso brasileiro. A reflexão de Honneth oferece insumos preciosos para pensar a injustiça racial. Infelizmente, neste artigo, não caberia realizar uma operacionalização mais ampla e sistemática dessa matriz interpretativa para investigar opressões e lutas raciais no Brasil. Tal empreitada requereria um trabalho de maior fôlego, que articulasse, com os devidos detalhes, as proposições conceituais de Honneth com os meandros históri$\cos$ da questão racial no país. Cabe-nos, todavia, indicar o tipo de agenda que poderia se desdobrar dessa matriz, bem como trazer alguns insights daí derivados.

A reflexão de Honneth permite pensar, em primeiro lugar, a existência de um conjunto de pessoas que teve suas chances de autorrealização estruturalmente negadas. Trata-se de sujeitos historicamente violentados do ponto de vista físico e psicológico; de pessoas que foram incluídas na sociedade em condições absolutamente assimétricas, sem acesso a direitos fundamentais, porque vistas como não pessoas; de sujeitos destituídos de singularidade, porque frequentemente estereotipados como parte de um coletivo negativizado. As noções de autoconfiança, autorrespeito e autoestima, vinculadas aos domínios do amor, do direito e da solidariedade, permitem-nos compreender a forma como o desrespeito e a opressão atravessam estruturalmente os sujeitos (Honneth, 2003a). Ao fazê-lo, tais noções nos interpelam a considerar a centralidade do processo de constituição de selves para a política, indicando, ainda, a necessidade de superação da dicotomia entre público e privado.

Em segundo lugar, o legado de Honneth permite ler, com a devida complexidade, situações de reconhecimento ideológico. As ideias de 
Freyre podem ter questionado o racismo essencialista de fundo spenceriano, o que, inclusive, emprestou-lhes legitimidade. No entanto, elas alimentaram uma alegada positivação do negro que sustenta o desrespeito e a injustiça em relação a esses sujeitos, seja porque o valorizam como mero corpo em movimento (no trabalho, no sexo, na dança, no esporte), seja porque impulsionam o mito de uma sociedade harmônica que não necessita de mudanças estruturais e de políticas raciais ${ }^{8}$. Pensar a questão racial no Brasil a partir de Honneth implica reconhecer a complexidade de um discurso de valorização que minou as condições, não apenas culturais, mas também institucionais, de autorrealização de milhões de pessoas.

A perspectiva de Honneth permite, em terceiro lugar, a compreensão dos processos históricos de luta em torno da questão racial. No caso brasileiro, a luta pela demarcação de áreas remanescentes de quilombos e a ação de movimentos como o Teatro Experimental do Negro (TEN) e o Movimento Negro Unificado (MNU) são importantes exemplos de como os debates em torno da questão racial têm tomado para si dimensões de luta pertencentes tanto ao reconhecimento de uma cultura peculiar, como à constatação de desigualdades estruturais. Esses conflitos nascem da percepção da inaceitabilidade moral das injustiças, da indignação gerada pelo desrespeito e da construção de semânticas coletivas que alimentam processos de confronto político. Cabe lembrar que este é, justamente, o alicerce teórico-interpretativo de Honneth (2003a) para compreender as lutas sociais.

Atores (individuais e coletivos) lutaram arduamente para evidenciar como o desrespeito a negros e negras viola dimensões fundamentais das gramáticas morais vigentes, cerceando as possibilidades de autorrealização de uma ampla parcela da população brasileira. Essas lutas buscam combater violências, desigualdades estruturais (incluindo as econômicas) e a vexação pública que impedem que negros e negras tenham condições básicas de justiça. Novamente, aqui, os domínios trabalhados por Honneth (2003a) (vínculos afetivos fortes, direitos e solidariedade) podem oferecer bases conceituais adequadas para pensar não apenas as opressões existentes, mas as múltiplas raízes de indignação que impulsionam os conflitos.

Nesse sentido, conquistas recentes do Estado brasileiro, como o Estatuto da Igualdade Racial podem ser vistas como conquistas dessas lutas moralmente motivadas, que alteram práticas sociais por meio de 
políticas e mudanças interpretativas. A contribuição de Honneth reside justamente na percepção do fundo moral a atravessar os conflitos e o processo de transformação da realidade ${ }^{9}$. A teoria do reconhecimento de Honneth oferece bases sólidas para pensar a necessidade de políticas públicas e mudanças institucionais no sentido de promoção de uma sociedade mais justa. Ela o faz inserindo tais conquistas em um processo mais amplo de transformação moral da sociedade, alimentado pelas lutas e resistências daqueles e daquelas que se opuseram a injustiças. Lutas essas, vale lembrar, atravessadas por processos intersubjetivos e políticos de configuração de selves.

O que argumentamos, assim, é que a perspectiva de Honneth permite a construção de um argumento muito semelhante ao de Avritzer e Gomes (2013) sem incorrer em alguns problemas da aproximação feita pelos autores entre Honneth e Fraser. Tal como delineada por Avritzer e Gomes, a articulação entre Honneth e Fraser acabou por alimentar uma dura clivagem entre público e privado na teoria da justiça, produzindo uma visão focada em etapas. Em vez de discutir a transformação moral da sociedade em suas múltiplas dimensões, prescreve-se um momento mais institucionalizado e outro momento de transformação de perspectivas mais privadas, individuais. Instituições e comportamentos são, de algum modo, dissociados na solução prescrita.

Além disso, a mobilização de Fraser para pensar justamente a questão das cotas requereria uma discussão sobre suas críticas a políticas afirmativas, visto que a autora não as vê como capazes de afetar estruturalmente as causas da opressão. Mesmo que Fraser (2003) reconheça que pode haver reformas não reformistas com impacto estrutural a longo prazo, sua distinção entre soluções afirmativas e transformativas recomendaria certa cautela em relação à política de cotas. A questão, portanto, é que a articulação entre Fraser e Honneth, como proposta pelos autores, pode levar a consequências aplicadas e a novos dilemas para a superação das injustiças raciais.

\section{CONSIDERAÇÕES FINAIS}

Este artigo buscou evidenciar a proficuidade da abordagem honnethiana de reconhecimento para pensar a questão racial no Brasil. Argumentou-se que a perspectiva ajuda a compreender a dimensão moral da profunda exclusão racial existente no país, bem como as lutas históricas que se opõem ao desrespeito em sua multiplicidade de formas. 
Para evidenciar essa potencialidade da teoria de Honneth, o artigo deu especial atenção à desmistificação da ideia de que o reconhecimento é sinônimo de uma valorização simbólica e privada de identidades. A discussão do próprio filósofo alemão sobre o reconhecimento como ideologia ajuda a compreender que há formas não emancipatórias de valorização de atributos e práticas identitários.

O texto mobilizou essa ideia de reconhecimento ideológico para reler a contribuição de Gilberto Freyre à compreensão das relações raciais no Brasil. Ainda que Freyre rompa com as teses eugenistas para valorizar o negro na formação social do país, sua visão acaba por reforçar estruturas de dominação racial, ao limitar o horizonte de contribuição do negro e ao apaziguar o conflito e as assimetrias na história das relações raciais brasileiras. A ideia de reconhecimento como ideologia ajuda a ler a ambivalência do referido autor e as consequências duradouras desse tipo de pensamento na estruturação da ideia de um povo brasileiro e na opressão de negros e negras.

Por fim, e com base nessa releitura, o artigo faz um contraponto com a leitura que Avritzer e Gomes (2013) realizam da questão racial pelas lentes do reconhecimento. Apesar da concordância com o tom geral da interpretação dos pesquisadores, o presente artigo percebe como problemática a redução da abordagem de Honneth a um enfoque centrado na dimensão privada da justiça. Honneth não reforça a dicotomia entre público e privado, mas a desloca, evidenciando a dimensão profundamente política dos processos de formação de selves. Ademais, salienta-se o perigo de uma articulação entre Honneth e Fraser que os tome como balizadores de momentos distintos da promoção da justiça. Entende-se que a teoria do reconhecimento de Honneth oferece insumos para embasar um diagnóstico muito próximo do oferecido por Avritzer e Gomes sem incorrer nos riscos da leitura feita por eles.

(Recebido para publicação em dezembro de 2014)

(Reapresentado em maio de 2016)

(Aprovado para publicação em setembro de 2016) 


\section{NOTAS}

1. O conceito de raça cósmica (raza cósmica), tratado por José de Vasconcelos no México, também seria um exemplo da popularidade desta vertente entre os estudiosos latino-americanos à época.

2. O próprio Gilberto Freyre e, posteriormente, Darcy Ribeiro (1995) procuram desmistificar a visão de Euclides da Cunha a respeito das matrizes civilizatórias do sertão, alegando que o desbravamento dos confins do Nordeste e de Minas Gerais foram possibilitados pelo contingente de mamelucos, mestiços oriundos de uniões entre negros e índios.

3. Araújo (1994) explora, em sua interpretação sobre os escritos de Freyre - especialmente Casa Grande \& Senzala, as principais ambiguidades do autor pernambucano, $\mathrm{e}$ a forma com que essas ambiguidades se anulam, produzindo "antagonismos em equilíbrio". Esses antagonismos se expressariam em binômios como "intimidade e distância", "arsênico e alfazema" e, mais importante, "raça e cultura". Para Araújo, essas expressões retratam divergências que no interior da Casa-Grande se aproximariam, mas não chegariam a se dissolver.

4. Cabe lembrar, aqui, que ele se elegeu para a Assembleia Constituinte de 1946 pela UDN (União Democrática Nacional).

5. Freyre era amigo do general Castelo Branco, primeiro presidente do Regime Militar (1964-1985).

6. Agradecemos a um(a) do(a)s pareceristas anônimos de DADOS por sugerir que chamássemos a atenção, mais explicitamente, para este ponto.

7. Os livros citados aqui apresentam uma série de artigos publicados desde a década de 1980 que tratam centralmente da questão do trabalho e da dominação de classe.

8. Lembramos, novamente, que a obra de Freyre não desconsidera a (re)produção de violências no âmbito da sociedade colonial brasileira para com a população negra, escravizada ou livre. Concordamos que o foco excessivo nas características essencialmentes privatistas da empreitada escravista no Brasil deixa de lançar luz sobre a expressão pública das identidades raciais, mas não se pode desconsiderar a abordagem freyreana (ainda que açucarada) das situações de vexação às quais a população negra esteve historicamente exposta na colônia. Mesmo assim, a análise da obra de Freyre sob o viés conceitual do reconhecimento ideológico não é invalidada, haja vista que Freyre se localiza entre um momento histórico da ciência brasileira que desvalorizava e minorava as contribuições civilizatórias da população negra e um momento de revisão da tradição sociológica brasileira e ponderação a respeito da relação entre público e privado na (re)produção de violências e desigualdades raciais.

9. Cabe destacar que a noção de reconhecimento está expressa no artigo 1 do Estatuto da Igualdade Racial (Brasil, 2010), que considera discriminação racial ou étnico-racial como "toda distinção, exclusão, restrição ou preferência baseada em raça, cor, descendência ou origem nacional ou étnica que tenha por objeto anular ou restringir o reconhecimento, gozo ou exercício, em igualdade de condições, de direitos humanos e liberdades fundamentais nos campos político, econômico, social, cultural ou em qualquer outro campo da vida pública ou privada". 


\section{Ricardo Fabrino Mendonça e Nathália França Figuerêdo Porto}

\section{REFERÊNCIAS BIBLIOGRÁFICAS}

ARAÚJO, Ricardo Benzaquen de. (1994), Guerra e Paz: Casa-Grande e Senzala e a Obra de Gilberto Freyre nos Anos 30. Rio de Janeiro, Ed. 34.

AVRITZER, Leonardo; GOMES, Lilian C. B. (2013), "Política de Reconhecimento, Raça e Democracia no Brasil". DADOS - Revista de Ciências Sociais, vol. 56, no 1, pp. 39-68.

BADER, Veit. (2007), "Misrecognition, Power and Democracy”, in B. Brink e D. Owen (orgs.), Recognition and Power: Axel Honneth and the Tradition of Critical Social Theory. Cambridge, Cambridge University Press, pp. 238-269.

BAILEY, Stanley. (2009), Legacies of Race: Identities, Attitudes and Politics in Brazil. Stanford, Stanford University Press.

BASTOS, Élide Rugai. (2006), As Criaturas de Prometeu: Gilberto Freyre e a Formação da Sociedade Brasileira. São Paulo, Global.

. (2012), "Gilberto Freyre e seu Tempo: Contexto Intelectual e Questões da Época". Sinais Sociais, vol. 19, pp. 60-87.

BRASIL. (2010), Estatuto da Igualdade Racial (Lei no 12.288 / 2010). Brasília, Subchefia para Assuntos Jurídicos da Casa Civil da Presidência da República.

COUTINHO, Odilon Ribeiro. (2005), "Imagismo, Cor e Cadência”, in O. R. Coutinho, Gilberto Freyre ou o Ideário Brasileiro. Rio de Janeiro, Topbooks, pp. 101-103.

CUNHA, Euclides da. (1982), Os Sertões: Campanha de Canudos. São Paulo, Abril Cultural.

DAMATTA, Roberto. (2004), "O Brasil como Morada (Prefácio)", in G. Freyre, Sobrados e Mucambos: Decadência do Patriarcado Rural e Desenvolvimento do Urbano. São Paulo, Global.

DEGLER, Carl N. (1971), Nem Branco nem Preto: Escravidão e Relações Raciais no Brasil e nos Estados Unidos. Rio de Janeiro, Labor do Brasil.

DERANTY, Jean Philippe; RENAULT, Emmanuel. (2007), "Politicizing Honneth's Ethics of Recognition". Thesis Eleven, vol. 88, no 1, pp. 92-111.

FELDMAN, Leonard. (2002), "Recognition, Redistribution and the State: The Irreducibly Political Dimension of Justice". Political Theory, vol. 30, no 3, pp. 410-440.

FORST, Rainer. (2007), “First Things First: Redistribution, Recognition and Justification". European Journal of Political Theory, vol. 6, no 3, pp. 291-304.

FRASER, Nancy. (2003), "Social Justice in the Age of Identity Politics: Redistribution, Recognition, and Participation", in N. Fraser; A. Honneth (orgs.), Redistribution or Recognition? A Political-Philosophical Exchange. London/New York, Verso.

. (2008), Scales of Justice. Reimagining Political Space in a Globalizing World. Malden, Polity Press.

FREYRE, Gilberto. (1973), Casa-Grande \& Senzala. Rio de Janeiro, José Olympio. . (2001), Interpretação do Brasil: Aspectos da Formação Social Brasileira como Processo de Amalgamento de Raças e Culturas. São Paulo, Companhia das Letras.

. (2004), Sobrados e Mucambos: Decadência do Patriarcado Rural e Desenvolvimento do Urbano. São Paulo, Global. 


\section{Reconhecimento Ideológico: Uma Reinterpretação...}

GUIMARÃES, Antônio S. (1999), Racismo e Antirracismo no Brasil. São Paulo, Editora 34.

HARTMANN, Martin; HONNETH, Axel. (2006), "Paradoxes of Capitalism". Constellations, vol. 13, no 1, pp. 41-58.

HONNETH, Axel. (1991), The Critique of Power. Cambridge, MIT Press.

. (1995), The Fragmented World of the Social: Essays in Social and Political Philosophy. New York, State University of New York Press.

. (2003a), Luta por Reconhecimento: A Gramática Moral dos Conflitos Sociais. São Paulo, Editora 34.

(2003b), "Redistribution as Recognition: A Response to Nancy Fraser", in N.

Fraser; A. Honneth (orgs.), Redistribution or Recognition: A Political-philosophical Exchange. London/New York, Verso, pp. 110-197.

. (2007), "Recognition as Ideology", in B. Brink; D. Owen (orgs.), Recognition and Power: Axel Honneth and the Tradition of Critical Theory. Cambridge, Cambridge University Press.

. (2012), The I in We: Studies in the Theory of Recognition. Malden, Polity Press.

. (2014), Freedom's Right: The Social Foundations of Democratic Life. New York, Columbia University Press.

LEHMANN, David. (2008), "Gilberto Freyre: A Reavaliação Prossegue". Horizontes Antropológicos, vol. 4, no 29, pp. 369-385.

MARKELL, Patchen. (2000), "The Recognition of Politics: A Comment on Emcke and Tully". Constellations, vol. 7, no 4, pp. 496-506.

. (2003), Bound by Recognition. Princeton, Princeton University Press.

MCBRIDE, Cillian. (2009), "Demanding Recognition: Equality, Respect and Esteem”. European Journal of Political Theory, vol. 8, no 1, pp. 96-108.

MCNAY, Lois. (2008), Against Recognition. New York, Polity Press.

MENDONÇA, Ricardo Fabrino. (2007), "Reconhecimento em Debate: Os Modelos de Honneth e Fraser em sua Relação com o Legado Habermasiano". Revista de Sociologia e Política, no 29, pp. 169-185.

. (2009), “A Dimensão Intersubjetiva da Auto-realização: Em Defesa da Teoria do Reconhecimento". Revista Brasileira de Ciências Sociais, vol. 24, no 70, pp. 143-154.

. (2011). "Recognition and Social Esteem: A Case Study of the Struggles of People Affected by Leprosy". Political Studies, vol. 59, no 4, pp. 940-958.

. (2013), "Reconhecimento", in L. Avritzer et al. (orgs.), Dimensões Políticas da Justiça. Rio de Janeiro, Civilização Brasileira, pp. 117-131.

. (2014), "What if the Forms of Recognition Contradict Each Other? The Case of the Struggles of People Affected by Leprosy in Brazil". Constellations, vol. 21, pp. $32-49$.

OGANDO, Ana Carolina. (2012), Da República sem Mulheres à Modernização Patriarcal: Origens e Metamorfoses das Relações de Gênero no Brasil. Tese (Doutorado em Ciência Política), Universidade Federal de Minas Gerais, Belo Horizonte.

DADOS - Revista de Ciências Sociais, Rio de Janeiro, vol. 60, nº 1, 2017 


\section{Ricardo Fabrino Mendonça e Nathália França Figuerêdo Porto}

RAMOS, Jair de Souza. (2003), “Ciência e Racismo: Uma Leitura Crítica de Raça e Assimilação em Oliveira Vianna”. História, Ciência, Saúde - Manguinhos, vol. 10, no 2, pp. 573-601.

REIS, José Carlos. (2002), As Identidades do Brasil de Varnhagen a FHC. Rio de Janeiro, FGV Editora.

RIBEIRO, Darcy. (1995), O Povo Brasileiro: A Formação e o Sentido do Brasil. São Paulo, Companhia das Letras.

RODRIGUES, Raimundo Nina. (1899), Mestiçagem, Degenerescência e Crime. (Tradução de Mariza Corrêa). Lyon, A. Storck \& Cie Imprimeurs-Éditeurs.

SCHWARCZ, Lilia Moritz. (1993), O Espetáculo das Raças: Cientistas, Instituições e Questão Racial no Brasil, 1870-1930. São Paulo, Companhia das Letras.

SEGLOW, Jonathan. (2009), "Rights, Contribution, Achievement: Self-esteem as Achievement and Contribution". European Journal of Political Theory, vol. 8, no1, pp. 61-75.

TELLES, Edward E. (2003), Racismo à Brasileira: Uma Nova Perspectiva Sociológica. Rio de Janeiro, Relume Dumará.

THOMAZ, Omar Ribeiro. (2002), Ecos do Atlântico Sul: Representações sobre o Terceiro Império Português. Rio de Janeiro, Editora da UFRJ.

THOMPSON, Simon; YAR, Majid. (2011), The Politics of Misrecognition. Aldershot, Ashgate.

VIANNA, Francisco José Oliveira. (1934), Raça e Assimilação. São Paulo, Companhia Editora Nacional. . (1987), Populações Meridionais do Brasil. Niterói, Editora UFF.

YOUNG, Iris Marion. (2007), “Recognition of Love's Labor: Considering Axel Honneth's Feminism", in B. Brink; D. Owen (orgs.), Recognition and Power: Axel Honneth and the Tradition of Critical Theory. Cambridge, Cambridge University Press, pp. 189-212. 


\section{RESUMO}

Reconhecimento Ideológico: Uma Reinterpretação do Legado de Gilberto Freyre sob a Ótica da Teoria do Reconhecimento

Este artigo procura mobilizar a ideia honnethiana de reconhecimento para refletir sobre a questão racial no Brasil. Enfoca-se, especialmente, em como a noção de reconhecimento ideológico (ou distorcido) ajuda a compreender o ambivalente legado de Gilberto Freyre, que ressignifica o lugar de negros e negras na sociedade, sem descortinar-lhes, contudo, chances efetivas e sistemáticas de autorrealização. Com isso, questiona-se a ideia de que a abordagem de Axel Honneth estaria limitada a propor uma valorização simbólica de coletivos, que não alteraria padrões institucionalizados de subordinação social. Honneth, ao contrário, pretende renovar os alicerces da teoria crítica, oferecendo tanto uma maneira de realizar diagnósticos de opressões históricas, quanto caminhos para pensar uma emancipação efetivamente possível nos quadros da sociedade existente. Sua perspectiva não reduz os processos de formação do self a uma empreitada privada e pré-política, mas evidencia sua centralidade para compreender os conflitos que movem as gramáticas morais que balizam as interações sociais.

Palavras-chave: reconhecimento ideológico; Gilberto Freyre; Axel Honneth; questão racial; negro

\section{ABSTRACT \\ Ideological Recognition: A Reinterpretation of the Legacy of Gilberto Freyre from the Perspective of the Theory of Recognition}

The following article aims to mobilize the Honnethian idea of recognition in order to reflect on the issue of race in Brazil. It is particularly focused on how the notion of ideological (or distorted) recognition helps inform an understanding of the ambivalent legacy of Gilberto Freyre, which re-signifies the place for black populations in society without however revealing to them effective and systematic opportunities for self-realization. This then leads to a questioning of whether Axel Honneth's approach would be limited to proposing a symbolic appreciation of collectives that would not alter institutionalized patterns of social subordination. In actual fact, Honneth aims to renovate the very foundations of critical theory, providing both a means of diagnosing historical oppressions and pathways for conceiving of effective emancipation in the framework of existing society. His perspective does not reduce the processes of formation of the self to a private and pre-political endeavor, but instead highlights their centrality in order to understand the conflicts informing the moral grammars at the foundations of social interactions.

Key words: ideological recognition; Gilberto Freyre; Axel Honneth; issue of race; black 


\section{RÉSUMÉ}

Reconnaissance Idéologique: Une Réinterprétation de l'Héritage de Gilberto Freyre sous l'Optique de la Théorie de la Reconnaissance

Cet article mobilise l'idée de reconnaissance chère à Honneth pour mener une réflexion sur la question raciale au Brésil. Nous nous intéresserons particulièrement à la manière dont la notion de reconnaissance idéologique (ou déformée) peut nous aider à comprendre l'héritage ambivalent de Gilberto Freyre, qui a resignifié la place des Noir(e)s dans la société sans pour autant leur proposer de chances effectives et systématiques d'autoréalisation. On souhaite ainsi remettre en question l'idée selon laquelle l'approche d'Axel Honneth se limiterait à proposer une valorisation symbolique de collectifs qui ne modifierait pas les normes institutionnalisées de subordination sociale. Honneth prétend au contraire renouveler les bases de la théorie critique en offrant aussi bien une manière de réaliser des diagnostics d'oppressions historiques que des voies pour penser une émancipation effectivement possible dans les cadres de la société existante. Sa perspective ne réduit pas les processus de constitution du Soi à une entreprise privée et pré-politique, mais met plutôt en évidence leur centralité dans la compréhension des conflits qui agitent les grammaires morales à la base des interactions sociales.

Mots-clés: reconnaissance idéologique; Gilberto Freyre; Axel Honneth; question raciale; noir

\section{RESUMEN}

Reconocimiento Ideológico: Una Reinterpretación del Legado de Gilberto Freyre desde la Óptica de la Teoría del Reconocimiento

Este artículo pretende movilizar la idea honnethiana de reconocimiento para reflexionar sobre la cuestión racial en Brasil. Se centra, en especial, en la manera en que la noción de reconocimiento ideológico (o distorsionado) ayuda a comprender el ambivalente legado de Gilberto Freyre, que reconsidera el lugar de la comunidad negra en la sociedad, pero sin mostrarle con ello oportunidades efectivas y sistemáticas de autorrealización. De este modo, se cuestiona la idea de que el enfoque de Axel Honneth se limita a proponer una valorización simbólica de colectivos que no altera patrones institucionalizados de subordinación social. Al contrario, se considera que Honneth busca renovar las bases de la teoría crítica, ofreciendo tanto una manera de realizar diagnósticos de opresiones históricas como vías para fraguar una emancipación efectivamente posible en el contexto de la sociedad existente. Su perspectiva no reduce los procesos de formación del self a una labor privada y prepolítica, sino que evidencia su centralidad para comprender los conflictos que impulsan las gramáticas morales limitadoras de las interacciones sociales.

Palabras clave: reconocimiento ideológico; Gilberto Freyre; Axel Honneth; cuestión racial; negro 